\title{
Recent Developments on Representation of Experimental Data by Polynomial Curve
}

\author{
Biswajit Das \\ Department of Mathematics, Chhaygaon College, Chhaygaon \\ E-mail: ccbiswajitdas@gmail.com
}

\begin{abstract}
Description / explanation of experimental data by mathematical curve / equation is one of the vital tools of analysis of data. Recently, some studies have been made on mathematical representation of experimental data on a pair of variables. In this context, a number of formulas based on mathematical operation Like forward difference operation, backward difference operation, divided difference operation, backward divided difference operation, difference \& ratio operation and backward difference \& ratio operation for explaining the data on a pair of variables by suitable mathematical equation / curve. Moreover, some methods based on matrix inversion by Cayley-Hamilton Theorem, Gauss Jordan method and elementary column transformation have been derived for the same purpose in connection with the searching for some more meritorious formula / method of interpolation. A summative description of these formulas / methods has been discussed in this paper along with their applications in numerical data.
\end{abstract}

Keywords: Pair of variables, experimental data, mathematical representation, polynomial curve.

\section{Introduction}

Observations or data, collected from experiment or survey, normally suffer from various types of errors / causes which can be broadly divided into two types namely (1) Assignable error / cause that is avoidable / controllable \& (2) Chance error / cause that is unavoidable / uncontrollable [Chakrabarty (2014a , 2014b , 2014c , 2014e , 2014f , 2014g , 2014h , 2015a , 2015b , 2015c , 2015d , 2015e)]. Even if all the assignable causes of error are controlled or eliminated, observations still do not become free from error. Each of them still suffers from some error which occurs due to some unknown and unintentional cause 
that is nothing but the chance cause. Consequently the findings obtained by analyzing the observations which are free from the assignable errors are also subject to errors due to the presence of chance error in the observations. Determination of constant(s) associated to mathematical model(s), in different situations, based on the observations is also subject to error due to the same reason.

A number of mathematical models have been identified for describing the association of chance error(s) in determining constant(s) in some distinct situations where observations/data are of measurement type [Chakrabarty (2014f , 2016a , 2016b , 2017e)].

There are two broad aspects of statistical determination of parameters involved in the respective models describing the dependence of the dependent variable on the independent variable(s). One of them is based on the basic philosophy behind statistics [Chakrabarty (2018a, 2018g, 2019c)], which consists of determining the parameter(s) from numerical data compromising with some degree of error in findings. Several statistical methods have already been developed for determination (estimation in statistical literature) of such parameter(s) which are available in the standard literatures in statistics. However, existing statistical methods of estimation cannot normally yield error free estimate(s) of parameters [Chakrabarty (2014f, 2016a, 2016b)]. The same fact happens in the case of some recently developed methods of estimation [Chakrabarty (2011, 2014d, 2016c, 2016d, 2016e), Chakrabarty \& Dutta (2007), Chakrabarty \& Rahman (2007, 2008)]. Recently, some studies have been made on attempting of determining error free estimates of such parameter(s) [Chakrabarty $(2014 \mathrm{~b}, 2014 \mathrm{f}, 2014 \mathrm{~h}$, 2015a , 2015d , 2015e , 2017f , 2017g , 2018d , 2019d , 2019i , 2020b)] along with attempting of application in the case of real data [Chakrabarty $(2015 c, 2015-16,2019 b, 2019 e)]$. These studies have been done on the basis of various measures of average namely the three Pythagorean means (namely arithmetic mean, geometric mean \& harmonic mean), median, generalized mean and others [Chakrabarty (2016h , 2017f , 2018b , 2018c , 2018d , 2018e , 2018f , 2019a , 2019f , 2019g , 2019h , 2020a)].

Standard methods of statistical representation of numerical data like least squares method, orthogonal polynomial method etc. is available in the standard literature of statistics. Some studies, extension in nature, have recently been done on statistical representation of numerical data by some special mathematical curves namely linear curve, quadratic curve, exponential curve etc. [Chakrabarty (2011, 2014d , 2016c , 2016d , 2017a), Chakrabarty \& Dutta (2007), Rahman \& Chakrabarty (2007, 2008 , 2009 , 2011 , 2015a , 2015b , 2015c , 2015d , 2015e , 2015f ,)], 
The recent trend is towards the study on the representation of numerical data on a pair of variables by suitable mathematical equation / mathematical curve [Chakrabarty (2016e , 2016f , 2016g , 2016h , 2016i , 2016 - 17 , 2017b , 2017c , 2018h), Das \& Chakrabarty (2016a , 2016b , 2016c , 2016d , 2016e , $2016 f$ , 2017a 2017b , 2017c , 2017d)] in connection with the development of some more meritorious formula / method of interpolation which is a technique of estimating approximately the value of the dependent variable corresponding to a value of the independent variable lying between its two extreme values on the basis of the given values of the independent and the dependent variables [Hummel (1947), Erdos Turan (1938), Bathe \& Wilson (1976), Jan (1930), Hummel (1947) et al].

The following formulas / methods have been developed in this studies:

(1) One formula (Das \& Chakrabarty, 2016a) based on usual algebraic operation.

(2) One formula (Das \& Chakrabarty, 2016c) based on forward difference operation.

(3) One formula (Das \& Chakrabarty, 2016d) based on backward difference operation.

(4) One formula (Das \& Chakrabarty, 2016b) based on divided difference operation.

(5) One method (Das \& Chakrabarty, 2016e) based on matrix inversion by Cayley-Hamilton Theorem [Cayley $(1858,1889) \&$ Hamilton (1864a, 1864b, 1862)].

(6) One method (Das \& Chakrabarty, 2016f) based on matrix inversion by Gauss Jordan method [Grcar\& Joseph (2011a, 2011b); Kaw, Autar, Kalu \& Egwu (2010)] which is based on elementary row transformation.

(7) One method (Das \& Chakrabarty, 2017a) based on matrix inversion by elementary column transformation.

(8) One formula (Das \& Chakrabarty, 2017b) based on backward divided difference operation.

(9) One formula (Chakrabarty, 2016g) based on difference and ratio operation.

(10) One formula (Chakrabarty, 2016 - 17) based on backward difference and ratio operation.

The first eight formulas / methods are the basic ones.

A summative description of these formulas / methods has been discussed in this paper along with their applications in numerical data.

\section{Formula / Method Representation of Numerical Data}


Formulas / methods of representation of numerical data on a pair of variables by suitable mathematical equation / mathematical curve, as mentioned above, have been discussed below:

\subsection{Forward Difference Formula:}

Let us consider the situation where the argument $x$ assume the values which are equally spaced i.e. $x$ assume the values at equal interval and let the length of the interval be $h$.

Thus,

$x_{i+1}-x_{i}=h,(i=0,1,2, \ldots \ldots, n-1)$

Let us define a variable $u$ by

$u=\frac{x-x_{0}}{h}$

Then the forward difference formula for representing a given set of numerical data on a pair of variables by a suitable polynomial curve in the situation where the argument assumes the values which are equally spaced i.e. the argument assumes the values at equal interval is given by

$$
y=f(x)=\alpha_{0} x^{0}+\alpha_{1} x^{1}+\alpha_{2} x^{2}+\ldots \ldots \ldots \ldots+\alpha_{n} x^{n}
$$

where

$$
\begin{aligned}
& \alpha_{0}=A_{0}-A_{1} x_{0}+A_{2} x_{0} x_{1}-A_{3} x_{0} x_{1} x_{2}+A_{4} x_{0} x_{1} x_{2} x_{3}- \\
& +A_{n}(-1)^{n}\left(x_{0} x_{1} x_{2} x_{3} \ldots \ldots \ldots x_{n-1}\right) \text {, } \\
& \alpha_{1}=A_{1}-A_{2}\left(\sum_{i=0}^{1} x_{i}\right)+A_{3}\left(\sum_{i=0}^{1} \sum_{j=1}^{2} x_{i} x_{j}\right)-
\end{aligned}
$$

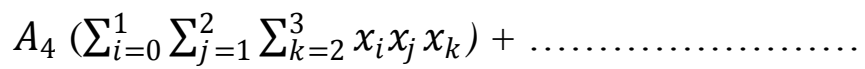

$$
\begin{aligned}
& +\ldots \ldots \ldots \ldots \ldots \ldots \ldots+(-1)^{n} A_{n}\left(x_{0} x_{1} x_{2} x_{3} \ldots \ldots \ldots x_{n-2}\right. \\
& \left.+x_{0} x_{1} x_{2} x_{3} \ldots \ldots \ldots \ldots x_{n-1}\right) \text {, } \\
& \alpha_{2}=A_{2}-A_{3}\left(\sum_{i=0}^{2} x_{i}\right)+A_{4}\left(\sum_{i=0}^{2} \sum_{j=1}^{3} x_{i} x_{j}\right) \\
& +(-1)^{n} A_{n}\left(x_{0} x_{1} x_{2} x_{3} \ldots \ldots \ldots x_{n-3}+x_{0} x_{1} x_{2} x_{3} \ldots \ldots \ldots x_{n-2}\right. \\
& \left.+x_{0} x_{1} x_{2} x_{3} \ldots \ldots \ldots \ldots x_{n-1}\right) \text {, } \\
& \alpha_{3}=A_{3}-A_{4}\left(\sum_{i=0}^{3} x_{i}\right)+\ldots \ldots \ldots+(-1)^{n} A_{n}\left(x_{0} x_{1} x_{2} x_{3} \ldots \ldots \ldots x_{n-4}\right. \\
& +x_{0} x_{1} x_{2} x_{3} \ldots \ldots \ldots x_{n-3}+x_{0} x_{1} x_{2} x_{3} \ldots \ldots \ldots x_{n-2}+x_{0} x_{1} x_{2} x_{3} \\
& \text {............... } x_{n-1} \text { ) }
\end{aligned}
$$


$\alpha_{i}=A_{i}-A_{i+1}\left(\sum_{j=0}^{i} x_{j}\right)+\ldots \ldots \ldots \ldots+(-1)^{n-i} A_{n}\left(x_{0} x_{1} x_{2} x_{3}\right.$

$\left.x_{n-i+1} \ldots \ldots \ldots \ldots+x_{0} x_{1} x_{2} x_{3} \ldots \ldots \ldots \ldots x_{n-1}\right)$

$\alpha_{n}=A_{n}$

with

$A_{0}=y_{0}, A_{1}=\frac{\Delta y_{0}}{h}, A_{2}=\frac{\Delta^{2} y_{0}}{2 ! h^{2}}, A_{i}=\frac{\Delta^{i-1} y_{0}}{(i-1) ! h^{i-1}}, \ldots \ldots \ldots \ldots \ldots, A_{n}=\frac{\Delta^{n} y_{0}}{n ! h^{n}}$

(Das \& Chakrabarty, 2016c).:

\subsection{Backward Difference Formula}

As in the earlier case, here also let us consider the situation where the argument $x$ assume the values which are equally spaced i.e. $x$ assume the values at equal interval and let the length of the interval be $h$. Thus,

$$
x_{i+1}-x_{i}=h,(i=0,1,2, \ldots \ldots, n-1)
$$

Let us define a variable $v$ by

$$
v=\frac{x-x_{n}}{h}
$$

Then the backward difference formula for representing a given set of numerical data on a pair of variables by a suitable polynomial curve in the situation where the argument assumes the values which are equally spaced i.e. the argument assumes the values at equal interval is given by

$$
y=f(x)=\beta_{0} x^{0}+\beta_{1} x^{1}+\beta_{2} x^{2}+\ldots \ldots \ldots \ldots+\beta_{n} x^{n}
$$

where

$$
\begin{aligned}
\beta_{0}= & B_{n}-B_{n-1} x_{n}+B_{n-2} x_{n} x_{n-1}-B_{n-3} x_{n-2} x_{n-1} x_{n}+ \\
& B_{n-4} x_{n-3} x_{n-2} x_{n-1} x_{n}-\ldots .(-1)^{n} B_{0}\left(x_{n} x_{n-1} x_{n-2} x_{n-3} \ldots \ldots \ldots x_{1}\right) \\
\beta_{1}= & B_{n-1}-B_{n-2}\left(\sum_{i=n-1}^{n} x_{i}\right)+B_{n-3}\left(\sum_{i=n-2}^{n-1} \sum_{j=n-1}^{n} x_{i} x_{j}\right)-B_{n-4} \\
& \left(\sum_{i=n-3}^{n-2} \sum_{j=n-2}^{n-1} \sum_{k=n-1}^{n} x_{i} x_{j} x_{k}\right)+\ldots \ldots \ldots .-B_{0}\left(\sum_{i=1}^{2} \sum_{j=2}^{1} \sum_{k=1}^{n} x_{i} x_{j} x_{k}\right) \\
\beta_{2}= & B_{n-2}-B_{n-3}\left(\sum_{i=n-2}^{n} x_{i}\right)+B_{n-4}\left(\sum_{i=n-3}^{n-1} \sum_{j=n-2}^{n} x_{i} x_{j}\right)-\ldots \ldots \ldots+ \\
& B_{0}\left(\sum_{i=2}^{3} \sum_{j=3}^{2} \sum_{k=2}^{1} \sum_{l=1}^{n} x_{i} x_{j} x_{k} x_{l}\right)
\end{aligned}
$$




$$
\begin{aligned}
\beta_{3}= & B_{n-3}-B_{n-4}\left(\sum_{i=n-3}^{n} x_{i}\right)+\ldots \ldots \ldots \ldots \ldots \ldots \ldots \\
& B_{0}\left(\sum_{i=3}^{4} \sum_{j=4}^{3} \sum_{k=3}^{2} \sum_{l=2}^{1} \sum_{m=1}^{n} x_{i} x_{j} x_{k} x_{l} x_{m}\right)
\end{aligned}
$$

$\beta_{n}=B_{n}$

with

$$
\begin{gathered}
B_{n}=f\left(x_{n}\right), B_{n-1}=\frac{\nabla f\left(x_{n-1}\right)}{h}, B_{n-2}=\frac{\nabla^{2} f\left(x_{n-2}\right)}{2 ! h^{2}}, B_{n-3}=\frac{\nabla^{3} f\left(x_{n-3}\right)}{3 ! h^{3}}, \\
B_{n-4}=\frac{\nabla^{4} f\left(x_{n-4}\right)}{4 ! h^{4}}, \ldots \ldots \ldots \ldots \ldots \ldots \ldots, B_{0}=\frac{\nabla^{n} f\left(x_{0}\right)}{n ! h^{n}}
\end{gathered}
$$

(Das \& Chakrabarty, 2016d).

\subsection{Divided Difference Formula:}

Let us now consider the situation where the argument $x$ as sume the values which are not equally spaced i.e. $x$ assume the values not at equal interval.

Then the divided difference formula, derived from Newton's divided difference interpolation formula [Chwaiger (1994), De Boor (2003), Gertrude (1954) et al], for representing a given set of numerical data on a pair of variables by a polynomial curve in the situation where the argument assume the values which are not necessarily equally spaced is given by

$$
y=f(x)=\gamma_{0} x^{0}+\gamma_{1} x^{1}+\gamma_{2} x^{2}+\ldots \ldots \ldots \ldots .+\gamma_{n} x^{n}
$$

where

$$
\begin{aligned}
& \gamma_{0}=D_{0}-D_{1} x_{0}+D_{2} x_{0} x_{1}-D_{3} x_{0} x_{1} x_{2}+D_{4} x_{0} x_{1} x_{2} x_{3}- \\
& +D_{n}(-1)^{n} \prod_{i=0}^{n-1} x_{i} \\
& \gamma_{1}=D_{1}-D_{2}\left(\sum_{i=0}^{1} x_{i}\right)+D_{3}\left(\sum_{i=0}^{1} \sum_{j=1}^{2} x_{i} x_{j}\right)-D_{4}\left(\sum_{i=0}^{1} \sum_{j=1}^{2} \sum_{k=2}^{3} x_{i} x_{j} x_{k}\right)+ \\
& +(-1)^{n} D_{n}\left(\prod_{i=0}^{n-2} x_{i}+\prod_{i=0}^{n-1} x_{i}\right) \\
& \gamma_{2}=D_{2}-D_{3}\left(\sum_{i=0}^{2} x_{i}\right)+D_{4}\left(\sum_{i=0}^{2} \sum_{j=1}^{3} x_{i} x_{j}\right)-\ldots \ldots(-1)^{n} D_{n}\left(\prod_{i=0}^{n-3} x_{i}+\prod_{i=0}^{n-2} x_{i}+\right. \\
& \left.\prod_{i=0}^{n-1} x_{i}\right) \\
& \gamma_{3}=D_{3}-D_{4}\left(\sum_{i=0}^{3} x_{i}\right)+\ldots \ldots \ldots .+(-1)^{n} D_{n}\left(\prod_{i=0}^{n-4} x_{i}+\prod_{i=0}^{n-3} x_{i} \prod_{i=0}^{n-2} x_{i}+\prod_{i=0}^{n-1} x_{i}\right) \\
& \gamma_{i}=D_{i}-D_{i+1}\left(\sum_{j=0}^{i} x_{i}\right)+\ldots \ldots \ldots+(-1)^{n-i} D_{n}\left(\prod_{i=0}^{n-i} x_{i}\right.
\end{aligned}
$$




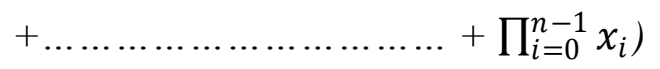

$\gamma_{n}=D_{n}$

with

$D_{0}=f\left(x_{0}\right)$,

$D_{1}=f\left(x_{0}, x_{1}\right)$,

$D_{2}=f\left(x_{0}, x_{1}, x_{2}\right)$,

$D_{3}=f\left(x_{0}, x_{1}, x_{2}, x_{3}\right)$,

$D_{i}=f\left(x_{0}, x_{1}, x_{2}, x_{3} \ldots x_{i}\right)$,

$D_{n}=f\left(x_{0}, x_{1}, x_{2}, x_{3} \ldots . . x_{n}\right)$

(Das \& Chakrabarty, (2016b).

\subsection{Algebraic Formula:}

Let the values of the independent variable $x$ be not necessary at equal interval.

Then the algebraic formula, obtained from Lagrange's interpolation formula [Whittaker \& Robinson (1967),

Echols (1893), Mills (1977) et al], for representing a given set of numerical data on a pair of variables by a polynomial curve in the situation where the argument assume the values which are not necessarily equally spaced is given by

$$
y=f(x)=\rho_{0} x^{0}+\rho_{1} x^{1}+\rho_{2} x^{2}+\ldots \ldots \ldots \ldots+\rho_{n} x^{n}
$$

where

$$
\begin{aligned}
& \rho_{0}=\sum_{i=0}^{n} L_{i} S_{i}(n), \\
& \rho_{1}=\sum_{i=0}^{n} L_{i} S_{i}(n-r), \\
& \rho_{2}=\sum_{i=0}^{n} L_{i} S_{i}(2), \\
& \rho_{3}=\sum_{i=0}^{n} L_{i} S_{i}(3),
\end{aligned}
$$

$\rho_{n-r}=\sum_{i=0}^{n} L_{i} S_{i}(r)$, 
$\rho_{n-2}=\sum_{i=0}^{n} L_{i} S_{i}(2)$,

$\rho_{n-1}=S_{i}(1)$,

$\rho_{n}=\sum_{i=0}^{n} L_{i}$

with

$$
\begin{gathered}
L_{0}=\frac{f\left(x_{0}\right)}{\prod_{i=0}^{n}\left(x_{0}-x_{i}\right)}, \\
L_{1}=\frac{f\left(x_{1}\right)}{\prod_{i=0}^{n}\left(x_{1}-x_{i}\right)} \\
i \neq 0, i \neq 1 \\
L_{n}=\frac{f\left(x_{n}\right)}{\prod_{i=0}^{n-1}\left(x_{n-1}-x_{i}\right)} \\
i \neq n-1
\end{gathered}
$$

and

$S_{r}=\sum_{\substack{i=0 \\ i \neq r}}^{n} x_{i} \quad, \quad S_{r}(p)=\sum_{i=0}^{n} \sum_{j=0}^{n} x_{i} x_{j}$
$i \neq r, j \neq r, i \neq j$

$S_{r_{1} r_{2} \ldots \ldots \ldots \ldots} r_{p}=\sum_{i_{1}=0}^{n} \sum_{i_{2}=0}^{n} \ldots \ldots \ldots . \sum_{i_{p}=0}^{n} x_{i_{1}} x_{i_{2}} \ldots \ldots . x_{i_{p}}$

$i_{1} \neq r_{1}, i_{2} \neq r_{1} \ldots \ldots \ldots i_{p} \neq r_{p}$

$i_{1} \neq i_{2} \neq----\neq i_{p}$

(Das \& Chakrabarty, 2016a).

\subsection{Backward Divided Difference Formula:}

As earlier let the values of the independent variable $x$ be not necessary at equal interval.

Then the backward divided difference formula for representing a given set of numerical data on a pair of variables by a polynomial curve in the situation where the argument assume the values which are not necessarily equally spaced is given by

$$
y=f(x)=\delta_{0} x^{0}+\delta_{1} x^{1}+\delta_{2} x^{2}+\ldots \ldots \ldots \ldots+\delta_{n} x^{n}
$$


where

$$
\begin{aligned}
\delta_{n}= & E_{n}-E_{n-1} x_{n}+E_{n-2} x_{n-1} x_{n}-E_{n-3} x_{n-2} x_{n-1} x_{n}+ \\
\ldots \ldots \ldots \ldots \ldots \ldots & +(-1)^{n} E_{0}\left(x_{n-1} x_{n-2} x_{n-3} \ldots \ldots \ldots \ldots x_{1} x_{0}\right) \\
\delta_{n-1}= & E_{n-1}-E_{n-2}\left(\sum_{i=\mathrm{n}-1}^{n} x_{i}\right)+E_{n-3}\left(\sum_{i=n}^{n-1} \sum_{j=n-1}^{n-2} x_{i} x_{j}\right)- \\
& +\ldots \ldots \ldots \ldots .+(-1)^{n} C_{0}\left(x_{n} x_{n-1} x_{n-2} x_{n-3} \ldots \ldots \ldots \ldots x_{1} x_{2}\right. \\
& \left.\quad+x_{n} x_{n-1} x_{n-2} x_{n-3} \ldots \ldots x_{1} x_{0}\right) \\
\delta_{n-2}= & E_{n-2}-E_{n-3}\left(\sum_{i=\mathrm{n}-2}^{n} x_{i}\right)+E_{n-4}\left(\sum_{i=\mathrm{n}-2}^{n} \sum_{j=\mathrm{n}-3}^{\mathrm{n}-1} x_{i} x_{j}\right)- \\
& \quad \ldots \ldots+(-1)^{n} E_{0}\left(x_{n} x_{n-1} x_{n-2} x_{n-3} \ldots x_{3}+\right. \\
& \left.\quad x_{n} x_{n-1} x_{n-2} x_{n-3} \ldots \ldots \ldots x_{2}+x_{n} x_{n-1} x_{n-2} x_{n-3} \ldots \ldots \ldots \ldots x_{1}\right) \\
\delta_{n-3}= & E_{n-3}-E_{n-4}\left(\sum_{i=\mathrm{n}-3}^{n} x_{i}\right)+\ldots \ldots . .+(-1)^{n} E_{0}\left(x_{n} x_{n-1} x_{n-2} x_{n-3}\right. \\
& \quad \ldots \ldots x_{4}+x_{n} x_{n-1} x_{n-2} x_{n-3} \ldots . x_{3}+x_{n} x_{n-1} x_{n-2} x_{n-3} \ldots \ldots x_{2} \\
& \left.+x_{n} x_{n-1} x_{n-2} \ldots \ldots \ldots x_{1}\right)
\end{aligned}
$$

$$
\delta_{n-i}=E_{n-i}-E_{n-(i+1)}\left(\sum_{i=\mathrm{n}-1}^{n} x_{i}\right)+\ldots \ldots \ldots \ldots+(-1)^{n-i} E_{0}
$$$$
\left(x_{n} x_{n-1} x_{n-2} \ldots \ldots \ldots . \quad x_{n-(i+1)}+\ldots \ldots \ldots \ldots \ldots \ldots+\right.
$$

$$
\left.x_{n} x_{n-1} x_{n-2} \ldots \ldots \ldots x_{1}\right)
$$

$\delta_{0}=E_{0}$

with

$$
\begin{aligned}
& E_{n}=f\left(x_{n}\right) \\
& E_{n-1}=f\left(x_{n}, x_{n-1}\right) \\
& E_{n-2}=f\left(x_{n}, x_{n-1}, x_{n-2}\right) \\
& E_{n-3}=f\left(x_{n}, x_{n-1}, x_{n-2}, x_{n-3}\right) \\
& E_{n-i}=\left(x_{n}, x_{n-1}, x_{n-2}, x_{n-3}, \ldots \ldots \ldots \ldots, x_{n-i}\right) \\
& E_{0}=f\left(x_{n}, x_{n-1}, x_{n-2}, x_{n-3}, \ldots \ldots \ldots \ldots, x_{0}\right)
\end{aligned}
$$

(Das \& Chakrabarty , 2017b). 


\subsection{Method of Representation by Matrix Inversion using Characteristic Equation:}

Suppose, $y_{i}$ denotes the value of the function (also called entry)

$$
y=f(x)
$$

corresponding to the value $x_{i}$ of the independent variable (also called argument) $x$ where $i$ assumes the integral values from 0 to $n$.

The problem here is to represent the $(n+1)$ pairs of values namely

$$
\left(x_{i}, y_{i}\right) \text {, for all } i \text {, }
$$

by the polynomial curve of the form

$$
y=f(x)=a_{0}+a_{1} x+a_{2} x^{2}+\ldots \ldots \ldots \ldots \ldots+a_{n} x^{n}, \quad a_{n} \neq 0
$$

Since the $(n+1)$ points lie on the curve describe by equation $(7)$,

$$
y_{i}=a_{0}+a_{1} x_{i}+a_{2} x_{i}{ }^{2}+\ldots \ldots \ldots \ldots \ldots+a_{n} x_{i}{ }^{n} \text {, for all } i \text {, }
$$

Solving these equations for the parameters, the form of the polynomial curve can be obtained which can represent the values of the $(n+1)$ pairs of values of the argument and entry.

The $(n+1)$ equations given by (7) can be expressed as

$$
\mathrm{A} X=\mathrm{B}
$$

where

(i) A is a square matrix of order $(n+1)$ given by

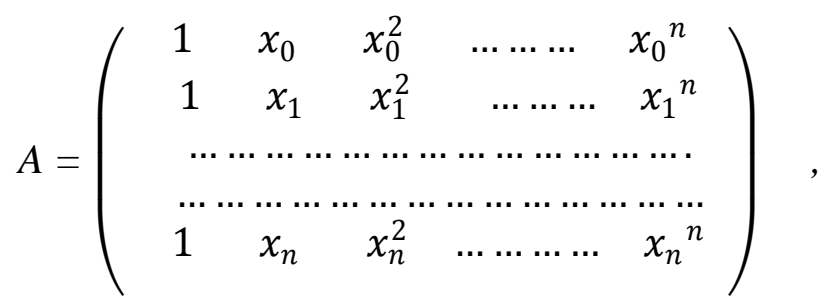

(ii) $X$ is a column vector of order $(n+1)$ given by

$$
X=\left(\begin{array}{c}
a_{0} \\
a_{1} \\
a_{2} \\
\cdot \\
\cdot \\
\cdot \\
a_{n}
\end{array}\right)
$$


$\&$ (iii) B is a column vector of order $(n+1)$ given by

$$
B=\left(\begin{array}{c}
y_{0} \\
y_{1} \\
y_{2} \\
\cdot \\
\cdot \\
\cdot \\
y_{n}
\end{array}\right)
$$

From equation (9), we get

$$
X=A^{-1} B
$$

This gives the values of the coefficients of the polynomial curve given by equation (6).

Thus, in order to find out the values of the above coefficients, it is essential to find out the inverse of the matrix A.

For finding out the inverse of the matrix A, one can apply the Cayley-Hamilton theorem [Cayley (1858), Cayley (1889),Hummel (1947), Hamilton (1864a) et al] on the characteristic equation of A given by

$$
\left|A-\lambda \cdot I_{n+1}\right|=0
$$

where $\lambda$ is the characteristic root (also known as the eigen value or the spectral value) of the matrix A and $I_{n+1}$ is the identity matrix of order $(\mathrm{n}+1)$.

Cayley-Hamilton theorem implies that every square matrix satisfies its own characteristic equation.

Thus,

$$
\left|A-A \cdot I_{n+1}\right|=0
$$

If the characteristic equation of the matrix $\mathrm{A}$ is given by equation (6) becomes of the form

$$
\lambda^{n}-c_{1} \lambda^{n-1}+c_{2} \lambda^{n-2}-c_{3} \lambda^{n-3}+\ldots \ldots \ldots+(-1)^{n} c_{n}=0
$$

after algebraic expansion, then by Cayley-Hamilton theorem the matrix $A$ will be the solution of $\lambda$ i.e.

$$
\lambda=A
$$

Hence from equation (12) it can be obtained that

$$
A^{-1}=-\frac{1}{(-1)^{n} c_{n}}\left[A^{n-1}-c_{1} A^{n-2}+c_{2} A^{n-3}-c_{3} A^{n-4}+\ldots \ldots \ldots+(-1)^{n-1} c_{n-1} I_{n+1}\right]
$$

[Cayley $(1858,1889)$, Hummel $(1947,1864 a)$, Das \& Chakrabarty $(2016 e)$,$] .$ 


\subsection{Method of Representation by Inversion of Matrix using Elementary Row}

\section{Transformation:}

In order to represent the $(n+1)$ pairs of values namely

$$
\left(x_{i}, y_{i}\right) \text {, for all } i \text {, }
$$

by the polynomial curve described by equation (6), it is necessary to solve the equations (7) for which it is again necessary to find out the inverse of the matrix A given by

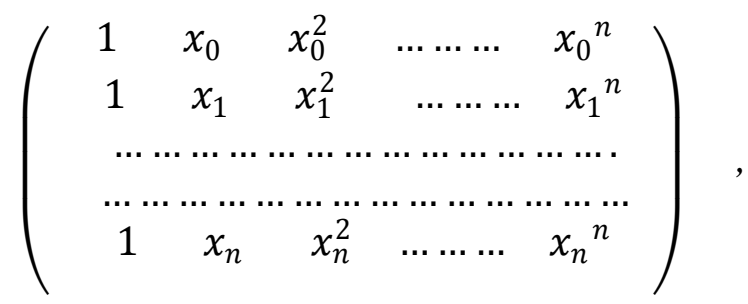

The inverse of the matrix A can also be found out by Gauss Jordan method [David (1991), Endre (2003) et al] which is based on elementary row transformations of matrix.

\section{Working rule:}

The working steps of finding inverse are as follows:

(i) Apply elementary row transformations on the matrix Ato obtain the identity matrix.

(ii) Apply the same elementary row transformations in the same order on the identity matrix.

(iii) The transformed matrix obtained from the identity matrix is the required inverse matrix of the matrix $A$.

Thus in order to find the inverse of $A$ by E-row operations, we write $A$ and the identity matrix $I$ side by side and the same operations are performed on both. As soon as the matrix $A$ is reduced to the identity matrix $I$ the identity matrix $I$ will reduce to $A^{-1}$ [David (1991), Endre (2003), Das \& Chakrabarty (2016f)].

\subsection{Method of Representation by Inversion of Matrix using Elementary Column}

\section{Transformation:}

In order to represent the $(n+1)$ pairs of values namely

$$
\left(x_{i}, y_{i}\right) \text {, for all } i \text {, }
$$


by the polynomial curve described by equation (6), it is necessary to solve the equations (8) for which it is again necessary to find out the inverse of the matrix A given by

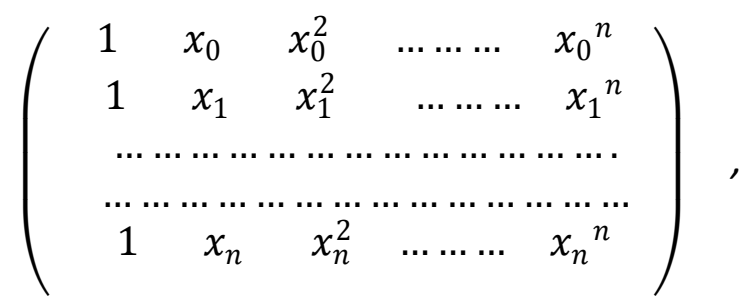

\section{Working rule:}

The working steps of finding inverse are as follows:

(i) Apply elementary column transformations on the matrix $A$ to obtain the identity matrix.

(ii) Apply the same elementary column transformations in the same order on the identity matrix.

(iii) The transformed matrix obtained from the identity matrix is the required inverse matrix of the matrix $A$.

Thus in order to find the inverse of $A$ by E-column operations, we write $A$ and the identity matrix I side by side and the same operations are performed on both. As soon as the matrix $A$ is reduced to the identity matrix $I$, the identity matrix $I$ will reduce to $A^{-1}$ [David (1991), Endre (2003), Das \& Chakrabarty (2017a)].

\section{Application to Numerical Data}

If The following table shows the number of persons (in thousands) in the population of India:

Table - 3(i)

(Number of persons in the population of India)

\begin{tabular}{|c|c|c|c|c|c|}
\hline Year & 1971 & 1981 & 1991 & 2001 & 2011 \\
\hline $\begin{array}{c}\text { Number of persons } \\
\text { (in thousands) }\end{array}$ & 548159.652 & 683329.097 & 846302.688 & 1027015.247 & 1210193.422 \\
\hline
\end{tabular}

Taking 1971 as origin and changing scale by 1/10, one can obtain the following table for the values of the argument $x$ (representing year) and the entry $y=f(x)$ (representing the number of persons in the population of India): 
Table - 3(ii)

(Values of argument and entry of Number of persons in the population of India)

\begin{tabular}{|c|c|c|c|c|c|}
\hline Year $(i)$ & 1971 & 1981 & 1991 & 2001 & 2011 \\
\hline Value of $x_{\mathrm{i}}$ & 0 & 1 & 2 & 3 & 4 \\
\hline $\begin{array}{c}\text { Value of } \\
y_{\mathrm{i}}=f\left(x_{i}\right) \\
\text { (in thousands) }\end{array}$ & 548159.652 & 683329.097 & 846302.688 & 1027015.247 & 1210193.422 \\
\hline
\end{tabular}

Here, $x_{0}=0, x_{1}=1, x_{2}=2, x_{3}=3, x_{4}=4$

$f\left(x_{0}\right)=548159.652, f\left(x_{1}\right)=683329.097, f\left(x_{2}\right)=846302.688$,

$f\left(x_{3}\right)=1027015.247, f\left(x_{4}\right)=1210193.422$

\subsection{Representation by Forward Difference Formula:}

Applying the equations given in (2) it is found that

$$
\begin{aligned}
& A_{0}=548159.652, \\
& A_{1}=135169.445, \\
& A_{2}=13902.073, \\
& A_{3}=-1677.529, \\
& \& A_{4}=-217.007
\end{aligned}
$$

Accordingly,

$\alpha_{0}=548159.652$,

$\alpha_{1}=119214.356$,

$\alpha_{2}=16547.583$,

$\alpha_{3}=-375.487$,

$\& \alpha_{4}=-217.007$

Consequently, the equation of the polynomial that can represent the given numerical data becomes $f(x)=548159.652+119214.356 x+16547.583 x^{2}-375.487 x^{3}-217.007 x^{4}$

\subsection{Representation by Backward Difference Formula:}


Applying the equations given in (2) we obtain the following:

$B_{4}=1210193.422$,

$B_{3}=183178.175$,

$B_{2}=1232.808$,

$B_{1}=-2545.55866$,

$B_{0}=-217.00725$,

Accordingly, the following have been obtained:

$\beta_{0}=548159.652$,

$\beta_{1}=119214.35634$,

$\beta_{2}=16547.58219$,

$\beta_{3}=-375.48616$,

$\beta_{4}=-217.00725$

Consequently, the polynomial that can represent the given numerical data becomes

$f(x)=548159.652+119214.356 x+16547.583 x^{2}-375.487 x^{3}-217.007 x^{4}$

\subsection{Representation by Divided Difference Formula:}

Applying the equations given in (3) we obtain the following:

$D_{0}=548159.652$,

$D_{1}=135169.445$,

$D_{2}=13902.073$,

$D_{3}=-1677.52966$,

$\& D_{4}=-217.00725$

Accordingly, the following have been obtained:

$\gamma_{0}=548159.652$,

$\gamma_{1}=119214.35618$,

$\gamma_{2}=16547.58223$,

$\gamma_{3}=-375.48616$,

$\& \gamma_{4}=-217.00725$ 
Consequently, the equation of the polynomial that can represent the given numerical data becomes Consequently, the polynomial that can represent the given numerical data becomes $f(x)=548159.652+119214.356 x+16547.583 x^{2}-375.487 x^{3}-217.007 x^{4}$

\subsection{Representation by Algebraic Formula:}

Applying the formulas of $L_{i}$, we obtain the following:

$$
\begin{aligned}
& L_{0}=22839.9855, \\
& L_{1}=-113888.18283, \\
& L_{2}=211575.672, \\
& L_{3}=-171169.20783, \\
& \& L_{4}=50424.72591 .
\end{aligned}
$$

Applying the formulas of $\rho_{i}$, we obtain the following:

$$
\begin{aligned}
& \rho_{0}=548159.652, \\
& \rho_{1}=-119214.356, \\
& \rho_{2}=16547.5823, \\
& \rho_{3}=375.4862, \\
& \& \rho_{4}=-217.00725
\end{aligned}
$$

Therefore, the polynomial that can represent the given numerical data becomes $f(x)=-217.00725 x^{4}-375.4862 x^{3}+16547.5823 x^{2}+119214.356 x+$ 548159.652

\subsection{Representation by Backward Divided Difference Formula:}

Applying the equations given in (5) we obtain the following:

$$
\begin{gathered}
E_{4}=1210193.422, \\
E_{3}=-183178.175, \\
E_{2}=1232.808, \\
E_{1}=2545.55866, \\
\& E_{0}=-217.00725
\end{gathered}
$$

Accordingly, the following have been obtained: 


$$
\begin{aligned}
& \delta_{4}=1210193.422, \\
& \delta_{3}=-178017.82218, \\
& \delta_{2}=-8790.94773, \\
& \delta_{1}=3847.60216, \\
& \delta_{0}=-217.00725
\end{aligned}
$$

Consequently, the equation of the polynomial that can represent the given numerical data becomes $f(x)=1210193.422-178017.82218 x-8790.94773 x^{2}+3847.60216 x^{3}$

$$
-217.00725 x^{4}
$$

\subsection{Representation by Cayley-Hamilton Theorem:}

Here

$X=\left(\begin{array}{l}a_{0} \\ a_{1} \\ a_{2} \\ a_{3}\end{array}\right) \quad, \quad A=\left(\begin{array}{llll}1 & 0 & 0 & 0 \\ 1 & 1 & 1 & 1 \\ 1 & 2 & 4 & 8 \\ 1 & 3 & 9 & 27\end{array}\right) \& B=\left(\begin{array}{c}548159.652 \\ 683329.097 \\ 846302.688 \\ 1027015.247\end{array}\right)$

In order to obtain the characteristic equation of $A$, it is necessary to expand the characteristic function $|A-\lambda \mathrm{I}|$.

Its algebraic expansion is

$$
\lambda^{4}-33 \lambda^{3}+94 \lambda^{2}-74 \lambda+12
$$

Therefore the characteristic equation of $A$ becomes

$$
\begin{gathered}
|A-\lambda I|=0 \\
\text { i.e. } \lambda^{4}-33 \lambda^{3}+94 \lambda^{2}-74 \lambda+12=0
\end{gathered}
$$

Application of Cayley Hamilton's theorem [Cayley (1858),Cayley (1889),Hummel (1947),Hamilton (1864a)et al] yield that

$A^{-1}=\frac{1}{12}\left[-A^{3}+33 A^{2}-94 A+74 \mathrm{I}\right]$

Now , numerical values $A^{2} \& A^{3}$ are as follows:

Now, $A^{2}=A . A=\left(\begin{array}{cccc}1 & 0 & 0 & 0 \\ 4 & 6 & 14 & 36 \\ 15 & 34 & 90 & 250 \\ 40 & 102 & 282 & 804\end{array}\right)$, 
$A^{3}=A^{2} \cdot A=\left(\begin{array}{cccc}1 & 0 & 0 & 0 \\ 60 & 142 & 386 & 1090 \\ 389 & 964 & 2644 & 7504 \\ 1228 & 3078 & 8466 & 24066\end{array}\right)$

Therefore,

$A^{-1}=\left(\begin{array}{cccc}1 & 0 & 0 & 0 \\ \frac{-11}{6} & 3 & \frac{-3}{2} & \frac{1}{-3} \\ 1 & \frac{-5}{2} & 2 & \frac{-1}{2} \\ \frac{-1}{6} & \frac{1}{2} & \frac{-1}{2} & \frac{1}{6}\end{array}\right)$

Consequently, from

$$
A X=B
$$

it has been obtained that

$$
X=A^{-1} B=\left(\begin{array}{c}
548159.652 \\
117912.31266 \\
18934.662 \\
-1677.52967
\end{array}\right)
$$

Thus the polynomial curve representing the data becomes

$$
\begin{aligned}
y=f(x)= & 548159.652+117912.31266 x+18934.662 x^{2} \\
& -1677.52967 x^{3}
\end{aligned}
$$

\subsection{Representation by elementary row transformation of matrix:}

As earlier here also,

$X=\left(\begin{array}{l}a_{0} \\ a_{1} \\ a_{2} \\ a_{3}\end{array}\right) \quad, \quad A=\left(\begin{array}{llll}1 & 0 & 0 & 0 \\ 1 & 1 & 1 & 1 \\ 1 & 2 & 4 & 8 \\ 1 & 3 & 9 & 27\end{array}\right) \& \quad B=\left(\begin{array}{c}548159.652 \\ 683329.097 \\ 846302.688 \\ 1027015.247\end{array}\right)$

Applying the following order elementary row transformations:

$$
\begin{gathered}
\mathrm{R}_{2} \rightarrow \mathrm{R}_{2}-\mathrm{R}_{1}, \mathrm{R}_{3} \rightarrow \mathrm{R}_{3}-\mathrm{R}_{1}, \mathrm{R}_{4} \rightarrow \mathrm{R}_{4}-\mathrm{R}_{1}, \mathrm{R}_{3} \rightarrow \frac{1}{2} \mathrm{R}_{3}, \mathrm{R}_{3} \rightarrow \mathrm{R}_{3}-\mathrm{R}_{2}, \mathrm{R}_{4} \rightarrow \frac{1}{3} \mathrm{R}_{4}, \mathrm{R}_{4} \rightarrow \mathrm{R}_{4}-\mathrm{R}_{2} \\
\mathrm{R}_{4} \rightarrow \frac{1}{2} \mathrm{R}_{4}, \mathrm{R}_{4} \rightarrow \mathrm{R}_{4}-\mathrm{R}_{3}, \mathrm{R}_{3} \rightarrow \frac{1}{3} \mathrm{R}_{3}, \mathrm{R}_{3} \rightarrow \mathrm{R}_{4}-\mathrm{R}_{3}, \mathrm{R}_{2} \rightarrow \mathrm{R}_{2}-\mathrm{R}_{4}, \mathrm{R}_{3} \rightarrow-3 \mathrm{R}_{3} \\
, \mathrm{R}_{2} \rightarrow \mathrm{R}_{2}-\mathrm{R}_{3},
\end{gathered}
$$

on the matrix $A$ serially in the order, the matrix $A$ has been converted to the identity matrix. 
Now, on the applications of the same elementary raw transformations serially in the same order on the identity matrix of order 4 , the identity matrix has been converted into the matrix

$$
\left(\begin{array}{cccc}
1 & 0 & 0 & 0 \\
-\frac{11}{6} & 3 & -\frac{3}{2} & \frac{1}{3} \\
1 & -\frac{5}{2} & 2 & -\frac{1}{2} \\
-\frac{1}{6} & \frac{1}{2} & -\frac{1}{2} & \frac{1}{6}
\end{array}\right)
$$

Hence,

$$
A^{-1}=\left(\begin{array}{cccc}
1 & 0 & 0 & 0 \\
-\frac{11}{6} & 3 & -\frac{3}{2} & \frac{1}{3} \\
1 & -\frac{5}{2} & 2 & -\frac{1}{2} \\
-\frac{1}{6} & \frac{1}{2} & -\frac{1}{2} & \frac{1}{6}
\end{array}\right)
$$

Consequently, from

$A X=B$

it has been obtained that

$X=A^{-1} B=\left(\begin{array}{c}548159.652 \\ 117912.31266 \\ 18934.662 \\ -1677.52967\end{array}\right)$

Thus the polynomial curve representing the data becomes

$y=f(x)=548159.652+117912.31266 x+18934.662 x^{2}-1677.52967 x^{3}$

\subsection{Representation by elementary column transformation of matrix:}

As earlier here also,

$X=\left(\begin{array}{l}a_{0} \\ a_{1} \\ a_{2} \\ a_{3}\end{array}\right) \quad A=\left(\begin{array}{cccc}1 & 0 & 0 & 0 \\ 1 & 1 & 1 & 1 \\ 1 & 2 & 4 & 8 \\ 1 & 3 & 9 & 27\end{array}\right) \& B=\left(\begin{array}{c}548159.652 \\ 683329.097 \\ 846302.688 \\ 1027015.247\end{array}\right)$

Applying the following order of elementary column transformations: 
$\mathrm{C}_{4} \rightarrow \mathrm{C}_{4}-\mathrm{C}_{3}, \quad \mathrm{C}_{3} \rightarrow \mathrm{C}_{3}-\mathrm{C}_{2} \quad, \quad \mathrm{C}_{4} \rightarrow \frac{1}{2} \mathrm{C}_{4} \quad \mathrm{C}_{4} \rightarrow \mathrm{C}_{4}-\mathrm{C}_{3}, \mathrm{C}_{2} \rightarrow \mathrm{C}_{2}-\mathrm{C}_{4} \quad, \mathrm{C}_{3} \rightarrow \frac{1}{2} \mathrm{C}_{3}, \quad \mathrm{C}_{3} \rightarrow \mathrm{C}_{3}-\mathrm{C}_{4} \quad$

$\mathrm{C}_{2} \rightarrow \mathrm{C}_{2}-\mathrm{C}_{3} \quad, \mathrm{C}_{2} \rightarrow \mathrm{C}_{2}-\mathrm{C}_{3} \quad, \mathrm{C}_{1} \rightarrow \mathrm{C}_{1}-\mathrm{C}_{2} \quad, \mathrm{C}_{1} \rightarrow \mathrm{C}_{1}-\mathrm{C}_{3} \quad, \mathrm{C}_{4} \rightarrow \frac{1}{3} \mathrm{C}_{4} \quad, \quad \mathrm{C}_{1} \rightarrow \mathrm{C}_{1}-\mathrm{C}_{4}$

on the matrix $A$ serially in the order, the matrix $A$ has been converted to the identity matrix.

Now, on the applications of the same elementary column transformations serially in the same order on the identity matrix of order 4 , the identity matrix has been converted into the matrix

$$
\left(\begin{array}{cccc}
1 & 0 & 0 & 0 \\
-\frac{11}{6} & 3 & -\frac{3}{2} & \frac{1}{3} \\
1 & -\frac{5}{2} & 2 & -\frac{1}{2} \\
-\frac{1}{6} & \frac{1}{2} & -\frac{1}{2} & \frac{1}{6}
\end{array}\right)
$$

Hence

$$
A^{-1}=\left(\begin{array}{rrrc}
1 & 0 & 0 & 0 \\
-\frac{11}{6} & 3 & -\frac{3}{2} & \frac{1}{3} \\
1 & -\frac{5}{2} & 2 & -\frac{1}{2} \\
-\frac{1}{6} & \frac{1}{2} & -\frac{1}{2} & \frac{1}{6}
\end{array}\right)
$$

Consequently, from

$$
A X=B
$$

it has been obtained that

$$
X=A^{-1} B=\left(\begin{array}{c}
548159.652 \\
117912.31266 \\
18934.662 \\
-1677.52967
\end{array}\right)
$$

Thus the polynomial curve representing the data becomes

$$
y=f(x)=548159.652+117912.31266 x+18934.662 x^{2}-1677.52967 x^{3}
$$




\section{Conclusion:}

Each of the formulas / methods yields the values of the function $f(x)$ corresponding to the respective observed values as follows:

$$
\begin{aligned}
& f(0)=548159.652, \\
& f(1)=683329.097, \\
& f(2)=846302.688, \\
& \& f(3)=1027015.247 .
\end{aligned}
$$

Consequently, the Number of persons (in thousand) the population of India as yielded by the curves as follows:

Number of persons in the year $1971=548159.652$,

Number of persons in the year $1981=683329.097$,

Number of persons in the year $1991=846302.688$,

$\&$ Number of persons in the year $2001=1027015.247$.

Thus, the formulas / methods are equivalent so far as the estimated values yielded by them are concerned. It is to be noted that the degree of the polynomial is one less than the number of pairs of observations.

The polynomial that represents the given set of numerical data can be used for interpolation at any position of the independent variable lying within its two extreme values. Thus, these formulas / methods can be suitably used in interpolation.

These formulas / methods can also be suitably used in extrapolation and also in inverse interpolation as well as in inverse extrapolation.

.Reference Echols W. H., On Some Forms of Lagrange's Interpolation Formula, The Annals of Mathematics, Jstor, 8(1/6), 22-24, 1893.

Jan K. Wisniewski ,Note on Interpolation (in Notes), "Journal of the American Statistical Association, Jstor 25(170), 203-205, 1930.

Corliss J. J. ,Note on an Eatension of Lagrange's Formula,American Mathematical Monthly,Jstor, 45(2), $106-107,1938$.

Hummel P. M., A Note on Interpolation (in Mathematical Notes), American Mathematical Monthly, Jstor, 54(4), 218-219, 1947. 
Gertrude Blanch, On Modified Divided Differences, Mathematical Tables and Other Aids to Computation, Vol. 8, No. 45, 1-11, 1954.

Herbert E. Salzer, Multi-Point Generalization of Newton's Divided Difference Formula, Proceedings of the American Mathematical Society, Jstor, 13(2), 210—212, 1962.

TraubJ. F., On Lagrange-Hermite Interpolation, Journal of the Society for Industrial and Applied Mathematics, Jstor , 12(4), 886-891, 1964.

Jordan C, Calculus of Finite Differences,3rd ed, New York, Chelsea, 1965.

Quadling D. A., Lagrange's Interpolation Formula, The Mathematical Gazette,L(374), 372 -375,1966.

Whittaker E. T. and Robinson G, The Gregory-Newton Formula of Interpolation and An Alternative Form of the Gregory-Newton Formula, The Calculus of Observations: A Treatise on Numerical Mathematics, 4th ed, pp. 10-15, 1967.

Whittaker E. T. \& Robinson G., Divided Differences \& Theorems on Divided Differences, The Calculus of Observations: A Treatise on Numerical Mathematics ,4 ${ }^{\text {th }}$ ed., New York, 20-24, 1967.

Abramowitz M, Handbook of Mathematical Functions with Formulas, Graphs, and Mathematical Tables, 9th printing. New York: Dover, p. 880, 1972.

Bathe K. J. \& Wilson E. L. ,Numerical Methods in Finite Element Analysis, Prentice-Hall, Englewood Cliffs, NJ., 1976.

Mills T. M.,An introduction to analysis by Lagrange interpolation, Austral. Math.Soc. Gaz., 4(1), MathSciNet, $10-18,1977$.

Dokken T \&Lyche T, A divided difference formula for the error in Hermite interpolation ,BIT , 19, 540 $541,1979$.

Fred T, Recurrence Relations for Computing with Modified Divided Differences, Mathematics of Computation, Vol. 33, No. 148, 1265-1271, 1979.

Conte S.D. \& Carl de Boor ,Elementary Numerical Analysis, 3 Ed, McGraw-Hill, New York, USA., 1980.

Jeffreys H \&Jeffreys B.S., Divided Differences , Methods of Mathematical Physics , $3^{\text {rd }}$ ed, 260-264, 1988.

Lee E.T.Y., A Remark on Divided Differences, American Mathematical Monthly, Vol. 96, No 7, 618$622,1989$. 
Vertesi P, SIAM Journal on Numerical Analysis, Vol. 27, No. 5, pp. 1322-1331, Jstor, 1990.

David R. Kincard\& E. Ward Chaney ,Numerical analysis, Brooks /Cole, Pacific Grove, CA, 1991.

Chwaiger J., On a Characterization of Polynomials by Divided Differences, Aequationes Math, 48, 317 323, 1994.

C. F. Gerald \& P. O. Wheatley, Applied Numerical Analysis, fifth ed., Addison-Wesley Pub. Co., MA., 1994.

James B. Scarborough ,Numerical Mathematical Analysis, 6 Ed, The John Hopkins Press, USA, 1996.

Robert J. Schilling\& Sandra L. Harries ,Applied Numerical Methods for Engineers, Brooks /Cole, Pacific Grove, CA, 2000.

Revers \& Michael Bull, On Lagrange interpolation with equally spaced nodes, Austral. Math.SocMathSciNet., 62(3), 357-368, 2000.

S.C. Chapra\& R.P. Canale,Numerical Methods for Engineers, third ed., McGraw-Hill, NewYork, 2002.

Floater M, Error formulas for divided difference expansions and numerical differentiation, J. Approx. Theory, 122, 1-9, 2003.

De Boor C, A divided difference expansion of a divided difference, J. Approx. Theory ,122 , 10-12, 2003.

Endre S \& David Mayers, An Introduction to Numerical Analysis, Cambridge, UK, 2003.

Wang $\mathrm{X} \&$ Wang $\mathrm{H}$, Some results on numerical divided difference formulas, www.math.uga.edu/ mjlai/pub.html, 2003.

John H. Mathews \&KurtisD.Fink,Numerical methods using MATLAB, 4ed, Pearson Education, USA., 2004.

Wang $\mathrm{X} \&$ Yang $\mathrm{S}$, On divided differences of the remainder of polynomial interpolation, www.math.uga.edu/ mjlai/pub.html, 2004.

Chakrabarty Dhritikesh \& Dutta Kamal, A Method of Fitting Exponential Curve to Population of Indian, Int. J. Agricult. Stat. Sci., (ISSN : 0973 - 1903), 3(1), 109 - 113, 2007. Available at https://www.researchgate.net/profile/Dhritikesh_Chakrabarty/stats.

Chakrabarty Dhritikesh \& Rahman Atwar, Exponential Curve : Estimation Using the Just Preceeding Observation in Fitted Curve, Int. J. Agricult. Stat. Sci., (ISSN : 0973 - 1903), 3(2), 381 - 386, 2007. Available at https://www.researchgate.net/profile/Dhritikesh_Chakrabarty/stats. 
Chakrabarty Dhritikesh \& Rahman Atwar, Gompartz Curve : Estimation Using the Just Preceding Observation in Fitted Curve , Int. J. Agricult. Stat. Sci., (ISSN : 0973 - 1903), 4(2), 421-424, 2008. Available at https://ww w.researchgate.net/profile/Dhritikesh_Chakrabarty/stats.

Rahman Atwar \& Chakrabarty Dhritikesh, Linear Curve : A Simpler Method of Obtaining Least squares Estimates of Parameters, Int. J. Agricult. Stat. Sci., (ISSN : 0973 - 1903), 5(2), 415 - 424, 2009. Available at https://www.researchgate.net/profile/Dhritikesh_Chakrabarty/stats.

Ripa Akter Nasin, Analysis of Newton's Forward Interpolation Formula, International Journal of Computer Science \& Emerging Technologies (E-ISSN: 2044-6004), 12, Volume 1, Issue 4, 2010.

Chakrabarty Dhritikesh, Finite Difference Calculus: Method of Determining Least Squares Estimates, AryaBhatta J. Math. \&Info., 3(2), (ISSN : 0975 - 7139), 363 - 373, 2011. Available at www.abjni.com. Also available at https://www.researchgate.net/profile/Dhritikesh_Chakrabarty/stats.

Rahman Atwar \& Chakrabarty Dhritikesh, General Linear Curve : A Simpler Method of Obtaining Least squares Estimates of Parameters, Int. J. Agricult. Stat. Sci., (ISSN : 0973 - 1903), 7(2), 429 - 440, 2011. Available at https://www.researchgate.net/profile/Dhritikesh_Chakrabarty/stats.

Chakrabarty Dhritikesh, Temperature in Assam: Natural Extreme Value, J. Chem. Bio.Phy. Sci. (EISSN : 2249 - 1929), Sec. C, 4 (2), $1479-1488,2014 a$. Available at www.jcbsc.org .

Chakrabarty Dhritikesh, Determination of Parameter from Observations Composed of Itself and Errors, International Journal of Engineering Science and Innovative Technology, 3(2), (ISSN : 2139 - 5967), $304-311,2014 b$. Available at https://www.researchgate.net/profile/Dhritikesh_Chakrabarty/stats.

Chakrabarty Dhritikesh, Natural Interval of Monthly Extreme Temperature in the Context of Assam, $J$. Chem. Bio.Phy. Sci. Sec. (E- ISSN : 2249 - 1929), C, 4 (3), 2424-2433, 2014c.Available at www.jcbsc.org .

Chakrabarty Dhritikesh ,Curve Fitting: Step-Wise Least Squares Method, AryaBhatta J. Math. \&Info., 6(1), (ISSN : $0975-7139), \quad 15-24, \quad 2014 d$. Available at https://www.researchgate.net/profile/Dhritikesh_Chakrabarty/stats.

Chakrabarty Dhritikesh, Analysis of Errors Associated to Observations of Measurement Type, International Journal of Electronics and Applied Research (ISSN : 2395 - 0064), 1(1), 15 - 28, $2014 e$. Available at http://eses.net.in/ESESJournal.

Chakrabarty Dhritikesh, Observation Consisting of Parameter and Error: Determination of Parameter, NaSAEAST- 2014, Abstract ID: CMAST_NaSAEAST (Inv)-1401). 2014f. Available at https://www.researchgate.net/profile/Dhritikesh_Chakrabarty/stats. 
Chakrabarty Dhritikesh, Natural Limits of Annual Total Rainfall in the Context of India, Int. J. Agricult. Stat. Sci., 10(1), (ISSN : 0973 - 1903), $105-109,2014 g$. Available at https://www.researchgate.net/profile/Dhritikesh_Chakrabarty/stats.

Chakrabarty Dhritikesh, Observation Composed of a Parameter and Chance Error: An Analytical Method of Determining the Parameter, International Journal of Electronics and Applied Research (ISSN : 2395 0064), 1(2), 20 - 38, 2014h. Available at http://eses.net.in/ESESJournal.

Rahman Atwar \& Chakrabarty Dhritikesh, "Elimination of Parameters and Principle of Least Squares: Fitting of Linear Curve to Average Minimum Temperature Data in the Context of Assam, International Journal of Engineering Sciences \& Research Technology, 4(2), (ISSN : 2277 - 9655), 255 - 259, $2015 a$. Available at https://www.researchgate.net/profile/Dhritikesh_Chakrabarty/stats.

Rahman Atwar \& Chakrabarty Dhritikesh, Elimination of Parameters and Principle of Least Squares: Fitting of Linear Curve to Average Maximum Temperature Data in the Context of Assam, AryaBhatta J. Math. \& Info. (ISSN (Print): 0975 - 7139, ISSN (Online): 2394 - 9309), 7(1), 23 - 28, 2015b. Available at www.abjni.com . Also available at https://www.researchgate.net/profile/Dhritikesh_Chakrabarty/stats.

Chakrabarty Dhritikesh, Observation Consisting of Parameter and Error: Determination of Parameter, Proceedings of the World Congress on Engineering (WCE) 2015, \{ISBN: 978-988-14047 ISSN: 20780958 (Print); ISSN: 2078-0966 (Online)\}, Vol. II, 680 - 684. Also in Lecture Notes in Engineering and Computer Science (ISBN: 978-988-14047-0-1), 2015, London, U.K., 680 - 684, 2015a. Available at https://www.researchgate.net/profile/Dhritikesh_Chakrabarty/stats.

Chakrabarty Dhritikesh, Central Tendency of Annual Extremum of Ambient Air Temperature at Guwahati, J. Chem. Bio. Phy. Sci. (E- ISSN : 2249 - 1929), Sec. C, 5(3), 2863 - 2877, 2015b. Available at www.jcbsc.org .

Rahman Atwar and Chakrabarty Dhritikesh, Basian-Markovian Principle in Fitting of Linear Curve, The International Journal Of Engineering And Science, \{ISSN (e): 2319 - 1813 ISSN (p): 2319 - 1805\} www.theijes.com), $4(6), \quad 31 \quad-\quad 43, \quad 2015 c$. Available at https://www.researchgate.net/profile/Dhritikesh_Chakrabarty/stats.

Rahman Atwar and Chakrabarty Dhritikesh, Basian-Markovian Principle in Fitting of Quadratic Curve, International Research Journal of Natural and Applied Sciences (ISSN: 2349 - 4077), www.aarf.asia , 2(6), $186-210,2015 d$. Available at https://www.researchgate.net/profile/Dhritikesh_Chakrabarty/stats.

Chakrabarty Dhritikesh, Central Tendency of Annual Extremum of Ambient Air Temperature at Guwahati Based on Midrange and Median, J. Chem. Bio. Phy. Sci. (E- ISSN : 2249 - 1929), Sec. D, 5(3), $3193-3204,2015$ c. Available at www.jcbsc.org .

Chakrabarty Dhritikesh, Observation Composed of a Parameter and Chance Error: Determining the Parameter as Stable Mid Range, International Journal of Electronics and Applied Research (ISSN : 2395 -0064), 2(1), 35 - 47, 2015d. Available at http://eses.net.in/ESESJournal. 
Chakrabarty Dhritikesh, A Method of Finding True Value of Parameter from Observation Containing Itself and Chance Error, Indian Journal of Scientific Research and Technology, (E-ISSN: 2321-9262), 3(4), $14-21,2015 e$. Available at http://www.indjsrt.com. Also available at https://www.researchgate.net/profile/Dhritikesh_Chakrabarty/stats.

Rahman Atwar \& Chakrabarty Dhritikesh, Method of Least Squares in Reverse Order: Fitting of Linear Curve to Average Maximum Temperature Data at Guwahati and Tezpur, International Journal in Physical \& Applied Sciences (ISSN: 2394 - 5710), www.ijmr.net.in, 2(9), 24 - 38, 2015e. Available at https://www.researchgate.net/profile/Dhritikesh_Chakrabarty/stats.

Rahman Atwar \& Chakrabarty Dhritikesh, Method of Least Squares in Reverse Order: Fitting of Linear Curve to Average Minimum Temperature Data at Guwahati and Tezpur ,AryaBhatta J. Math. \& Info. \{ISSN (Print): 0975 - 7139, ISSN (Online): 2394 - 9309\}, 7(2), 305 - 312, 2015f. Available at www.abjni.com . Also available at https://www.researchgate.net/profile/Dhritikesh_Chakrabarty/stats.

Chakrabarty Dhritikesh, Theoretical Model Modified For Observed Data: Error Estimation Associated To Parameter, International Journal of Electronics and Applied Research (ISSN : 2395 - 0064), 2(2), 29 45, 2015f. Available at http://eses.net.in/ESESJournal.

Chakrabarty Dhritikesh, Confidence Interval of Annual Extremum of Ambient Air Temperature at Guwahati, J. Chem. Bio. Phy. Sci. (E- ISSN : 2249 - 1929), Sec. C, 6(1), 192 - 203, 2015-16. Available at www.jcbsc.org.

Chakrabarty Dhritikesh, Impact of Error Contained in Observed Data on Theoretical Model: Study of Some Important Situations, International Journal of Advanced Research in Science, Engineering and Technology, (ISSN : 2350 - 0328), 3(1), 1255 - 1265, 2016a. Available at www.ijarset.com. Also available at https://www.researchgate.net/profile/Dhritikesh_Chakrabarty/stats.

Chakrabarty Dhritikesh, Theoretical Model and Model Satisfied by Observed Data: One Pair of Related Variables, International Journal of Advanced Research in Science, Engineering and Technology, (ISSN : 2350 - 0328), 3(2), 1527 - 1534, 2016b. Available at www.ijarset.com. Also available at https://www.researchgate.net/profile/Dhritikesh_Chakrabarty/stats.

Chakrabarty Dhritikesh, Elimination-Minimization Principle: Fitting of Polynomial Curve to Numerical Data, International Journal of Advanced Research in Science, Engineering and Technology, (ISSN : 2350 - 0328), 3(5), 2067 - 2078, 2016c. Available at www.ijarset.com. Also available at https://www.researchgate.net/profile/Dhritikesh_Chakrabarty/stats.

Chakrabarty Dhritikesh, Elimination-Minimization Principle: Fitting of Exponential Curve to Numerical Data, International Journal of Advanced Research in Science, Engineerin and Technology, (ISSN : 2350 - 0328), 3(6), 2256 - 2264, 2016d. Available at www.ijarset.com. Also available at https://www.researchgate.net/profile/Dhritikesh_Chakrabarty/stats. 
Chakrabarty Dhritikesh, Representation of Numerical Data on a Pair of Variables by a Polynomial Curve Expressed in the Simplest Form, International Journal of Electronics and Applied Research (ISSN : 2395 - 0064), 3(1), 26 - 39, 2016e. Available at http://eses.net.in/ESESJournal.

Das Biswajit \& Chakrabarty Dhritikesh, Lagrange's Interpolation Formula: Representation of Numerical Data by a Polynomial Curve, International Journal of Mathematics Trends and Technology (IJMTT) (ISSN: 2231 - 5373), 34(2), 64 - 72, 2016a. Available at http://www.ijmttjournal.org . Also available at https://www.researchgate.net/profile/Dhritikesh_Chakrabarty/stats.

Chakrabarty Dhritikesh, Interpolation: One Method of Representation of Numerical Data on a Pair of Variables by a Polynomial Curve Expressed In the Simplest Form, Journal of Environmental Science, Computer Science and Engineering \& Technology, Section C, (E-ISSN: 2278 - 179 X), 5(3), 405 - 418, 2016f. Available at www.jecet.org.

Das Biswajit \& Chakrabarty Dhritikesh, Newton's Divided Difference Interpolation Formula: Representation of Numerical Data by a Polynomial Curve, International Journal of Mathematics Trends and Technology (IJMTT) (ISSN: 2231 - 5373), 35(3), 197 - 203, 2016b. Available at http://www.ijmttjournal.org Also https://www.researchgate.net/profile/Dhritikesh_Chakrabarty/stats.

Das Biswajit \& Chakrabarty Dhritikesh, Newton's Forward Interpolation: Representation of Numerical Data by a Polynomial Curve, International Journal of Statistics and Applied Mathematics (IJMTT) (ISSN: 2456 - 1452), 1(2), 36 - 41, 2016c. Available at www.mathsjournal.com . Also available at https://www.researchgate.net/profile/Dhritikesh_Chakrabarty/stats.

Chakrabarty Dhritikesh, Difference and Ratio Operators: Representation of Numerical Data on a Pair of Variables by a Polynomial Curve, Journal of Environmental Science, Computer Science and Engineering \& Technology, Section C, (E-ISSN : 2278 - 179 X), 5(4), 549-560, 2016g. Available at www.jecet.org .

Das Biswajit \& Chakrabarty Dhritikesh, Newton's Backward Interpolation: Representation of Numerical Data by a Polynomial Curve, International Journal of Applied Research (IJAR) (ISSN Print: 2394-7500, ISSN Online: 2394-5869), 2(10), 513 - 517, 2016d. Available at www.allresearchjournal.com . Also available at https://www.researchgate.net/profile/Dhritikesh_Chakrabarty/stats.

Das Biswajit \& Chakrabarty Dhritikesh, Matrix Inversion: Representation of Numerical Data by a Polynomial Curve, Aryabhatta Journal of Mathematics \& Informatics \{ISSN (Print) : 0975-7139, ISSN (Online) : 2394-9309\}, 8(2), 267 - 276, 2016e. Available at www.abjni.com . Also available at https://www.researchgate.net/profile/Dhritikesh_Chakrabarty/stats.

Das Biswajit \& Chakrabarty Dhritikesh, Inversion of Matrix by Elementary Transformation: Representation of Numerical Data by a Polynomial Curve, Journal of Mathematics and Systems Sciences (ISSN : 0975 - 5454), 12(1-2), 27 - 32, 2016f. Available at www.abjni.com . Also available at https://www.researchgate.net/profile/Dhritikesh_Chakrabarty/stats. 
Chakrabarty Dhritikesh, Pythagorean Mean: Concept behind the Averages and Lot of Measures of Characteristics of Data, NaSAEAST-2016, Abstract ID: CMAST_NaSAEAST (Inv)-1601), $2016 h$. Available at https://www.researchgate.net/profile/Dhritikesh_Chakrabarty/stats.

Chakrabarty Dhritikesh, Recent Developments on Representation of Numerical Data by a Polynomial Curve, International Journal of Electronics and Applied Research (ISSN : 2395 - 0064), 3(2), 125 - 158, 2016i . Available at http://eses.net.in/ESESJournal.

Chakrabarty Dhritikesh, Backward Difference and Ratio Operations: Representation of Numerical Data on a Pair of Variables by a Polynomial Curve, Journal of Environmental Science, Computer Science and Engineering \& Technology, Section C, (E-ISSN : 2278 - 179 X), 6(1), 027 -039, 2016 - 17. Available at www.jecet.org .

Chakrabarty Dhritikesh, Elimination-Minimization Principle: Fitting of Gompertz Curve to Numerical Data, International Journal of Advanced Research in Science, Engineering and Technology, (ISSN : 2350 - 0328), 4(1), 3180 - 3189, 2017a. Available at www.ijarset.com. Also available at https://www.researchgate.net/profile/Dhritikesh_Chakrabarty/stats.

Das Biswajit \& Chakrabarty Dhritikesh, Inversion of Matrix by Elementary Column Transformation: Representation of Numerical Data by a Polynomial Curve, International Journal of Mathematics Trends and Technology (IJMTT) (ISSN: 2231 - 5373), 42(1), 45 - 49, 2017a. Available at http://www.ijmttjournal.org . Also available at https://www.researchgate.net/profile/Dhritikesh_Chakrabarty/stats.

Das Biswajit \& Chakrabarty Dhritikesh, Backward Divided Difference: Representation of Numerical Data by a Polynomial Curve, International Journal of Statistics and Applied Mathematics (ISSN: 2456 1452), 2(2), 1 - 6, 2017b. Available at http://www.mathsjournal.com. Also available at https://www.researchgate.net/profile/Dhritikesh_Chakrabarty/stats.

Das Biswajit \& Chakrabarty Dhritikesh, Representation of Numerical Data by Exponential Curve, Aryabhatta Journal of Mathematics \& Informatics \{ISSN (Print) : 0975-7139, ISSN (Online) : 23949309\}, 9(1), 157 - 162, 2017c. Available at www.abjni.com . Also available at https://www.researchgate.net/profile/Dhritikesh_Chakrabarty/stats.

Chakrabarty Dhritikesh, Some Forms of Interpolation Formula Based on Divided Difference, Journal of Environmental Science, Computer Science and Engineering \& Technology, Section C, (E-ISSN : 2278 179 X), 6(2), 199 - 211, 2017b. Available in www.jecet.org .

Chakrabarty Dhritikesh, Representation of Numerical Data by Some Special Mathematical Curves, International Journal of Electronics and Applied Research (ISSN : 2395 - 0064), 4(1), 52 - 74, 2017 c. Available at http://eses.net.in/ESESJournal. 
Das Biswajit \& Chakrabarty Dhritikesh, Representation of Numerical Data by Modified Exponential Curve, Journal of Mathematics and Systems Sciences (ISSN : 0975 - 5454), 13(1-2), 1 - 6, 2017d. Also available at www.abjni.com Also available at https://www.researchgate.net/profile/Dhritikesh_Chakrabarty/stats.

Chakrabarty Dhritikesh, Objectives and Philosophy behind the Construction of Different Types of Measures of Average, NaSAEAST- 2017, Abstract ID: CMAST_NaSAEAST (Inv)-1701), 2017f. Available at https://www.researchgate.net/profile/Dhritikesh_Chakrabarty/stats. .

Chakrabarty Dhritikesh, Variable(s) Connected by Theoretical Model and Model for Respective Observed Data, FSDM2017, Abstract ID: FSDM2220, 2017e. Available at https://www.researchgate.net/profile/Dhritikesh_Chakrabarty/stats.

Chakrabarty Dhritikesh, Observations Containing Single Parameter and Random Errors: One Method of Evaluation of the Parameter, Journal of Environmental Science, Computer Science and Engineering \& Technology, Section C, (E-ISSN : 2278 - 179 X), 6(4), 432 - 449, 2017f. Available at www.jecet.org.

Chakrabarty Dhritikesh, Numerical Data Containing One Parameter and Chance Error: Evaluation of the Parameter by Convergence of Statistic, International Journal of Electronics and Applied Research (ISSN : 2395 - 0064), 4(2), 59 - 73, 2017g. Available at http://eses.net.in/ESESJournal.

Chakrabarty Dhritikesh, Understanding the Space of Research, Biostatistics and Biometrics Open Access Journal, (ISSN: 2573-2633), 4(5), o01 - 017, 2018a. DOI: 10.19080/BBOAJ.2018.04.555642. Available at https://www.researchgate.net/profile/Dhritikesh_Chakrabarty/stats .

Chakrabarty Dhritikesh, Derivation of Some Formulations of Average from One Technique of Construction of Mean, American Journal of Mathematical and Computational Sciences, 3(3), 62 - 68, $2018 b$. Available at http://www.aascit.org/journal/ajmcs . Also available at https://www.researchgate.net/profile/Dhritikesh_Chakrabarty/stats.

Chakrabarty Dhritikesh, One Generalized Definition of Average: Derivation of Formulations of Various Means, Journal of Environmental Science, Computer Science and Engineering \& Technology, Section C, (E-ISSN : $2278-179$ X), 7(3), $212-225,2018 c$. Available atwww.jecet.org .

Das Biswajit \& Chakrabarty Dhritikesh, Numerical Data on a Pair of Variables: Representation by Logistic Curve, International Journal of Advanced Research in Science, Engineering and Technology, (ISSN : 2350 - 0328), 5(6), 6113 - 6119, 2018a. Available at www.ijarset.com. Also available at https://www.researchgate.net/profile/Dhritikesh_Chakrabarty/stats.

Chakrabarty Dhritikesh, Observed Data Containing One Parameter and Chance Error: Evaluation of the Parameter Applying Pythagorean Mean, International Journal of Electronics and Applied Research (ISSN : 2395 - 0064), 5(1), 32 - 45, 2018d. Available at http://eses.net.in/ESESJournal. 
Das Biswajit \& Chakrabarty Dhritikesh, Numerical Data on a Pair of Variables: Representation by Makeham's Curve, Aryabhatta Journal of Mathematics \& Informatics \{ISSN (Print) : 0975-7139, ISSN (Online) : 2394-9309\}, 10(2), 277 - 286, 2018b.Available at www.abjni.com . Also available at https://www.researchgate.net/profile/Dhritikesh_Chakrabarty/stats.

Chakrabarty Dhritikesh, $f_{H^{-}}$Mean: One Generalized Definition of Average", Journal of Environmental Science, Computer Science and Engineering \& Technology, Section C, (E-ISSN : 2278 - 179 X), 7(4), $301-314,2018 d$. Available at www.jecet.org . Also Available at https://www.researchgate.net/profile/Dhritikesh_Chakrabarty/stats.].

Chakrabarty Dhritikesh, Generalized $f_{G^{-}}$Mean: Derivation of Various Formulations of Average, American Journal of Computation, Communication and Control, 5(3), $101-108,2018$. Available at http://www.aascit.org/journal/ajmcs. Also available at https://www.researchgate.net/profile/Dhritikesh_Chakrabarty/stats.

Chakrabarty Dhritikesh, General Technique of Defining Average, NaSAEAST- 2018, Abstract ID: CMAST_NaSAEAST -1801 (I) 2018f. Available at https://www.researchgate.net/profile/Dhritikesh_Chakrabarty/stats.

Chakrabarty Dhritikesh, Statistics and Bioscience: Association in Research, Significances of Bioengineering \& Biosciences, (ISSN 2637-8078), 2(5), $001-007,2018 g$. DOI: 10.31031/SBB.2018.02.000546. Available at https://www.researchgate.net/profile/Dhritikesh_Chakrabarty/stats.

Chakrabarty Dhritikesh, Finite Difference and Ratio Operations: Representation of Numerical Data on a Pair of Variables by a Polynomial Curve, International Journal of Electronics and Applied Research (ISSN : 2395 - 0064), 5(2), 76 - 91, 2018h. Available at http://eses.net.in/ESESJournal.

Chakrabarty Dhritikesh, One Definition of Generalized $f_{G^{-}}$Mean: Derivation of Various Formulations of Average, Journal of Environmental Science, Computer Science and Engineering \& Technology, Section C, (E-ISSN : $2278-179$ X), 8(2), $051-066,2019 a$. Available at www.jecet.org .

Chakrabarty Dhritikesh, Significance of Change of Rainfall: Confidence Interval of Annual Total Rainfall, Journal of Chemical, Biological and Physical Sciences (E- ISSN : 2249 - 1929), Sec. C, 9(3), $151-166,2019 b$. Available at www.jcbsc.org .

Chakrabarty Dhritikesh, Association of Statistics with Biostatistics Research, Biometrics \& Biostatistics International Journal, 8(3), 104 - 109, 2019c. DOI: 10.15406/bbij.2019.08.00279 . Available at https://www.researchgate.net/profile/Dhritikesh_Chakrabarty/stats.

Chakrabarty Dhritikesh, Observed Data Containing One Parameter and Chance Error: Probabilistic Evaluation of Parameter by Pythagorean Mean, International Journal of Electronics and Applied Research (ISSN : 2395 - 0064), 6(1), 24 - 40, 2019d. Available at http://eses.net.in/ESES Journal). 
Chakrabarty Dhritikesh, Significance of Change in Ambient Air Temperature in the Context of India, Journal of Chemical, Biological and Physical Sciences (E- ISSN : 2249 - 1929), Sec. C, 9(4), 251 - 261, 2019e. Available at www.jcbsc.org .[

Chakrabarty Dhritikesh, One General Method of Defining Average: Derivation of Definitions/Formulations of Various Means, Journal of Environmental Science, Computer Science and Engineering \& Technology, Section C, (E-ISSN : 2278 - 179 X), 8(4), 327 - 338, 2019f. Available at www.jecet.org .

Chakrabarty Dhritikesh, A General Method of Defining Average of Function of a Set of Values, Aryabhatta Journal of Mathematics \& Informatics \{ISSN (Print) : 0975-7139, ISSN (Online) : 23949309\}, 11(2), $269-284,2019 g$. Available at www.abjni.com. Also available at https://www.researchgate.net/profile/Dhritikesh_Chakrabarty/stats.

Chakrabarty Dhritikesh, Pythagorean Geometric Mean: Measure of Relative Change in a Group of Variables, NaSAEAST-2019,Abstract ID: CMAST_NaSAEAST -1902 (I), 2019h. Available at https://www.researchgate.net/profile/Dhritikesh_Chakrabarty/stats .

Chakrabarty Dhritikesh, Arithmetic-Geometric Mean: Evaluation of Parameter from Observed Data Containing Itself and Random Error, International Journal of Electronics and Applied Research (ISSN : 2395 - 0064), 6(2), 98 - 111, 2019i. Av, ailable at http://eses.net.in/ESES Journal.

Chakrabarty Dhritikesh, Definition / Formulation of Average from First Principle, Journal of Environmental Science, Computer Science and Engineering \& Technology, Section C, (E-ISSN : 2278 179 X), 9(2), $151-163,2020 a$. Available at www.jecet.org .

Chakrabarty Dhritikesh, AGM: A Technique of Determining the Value of Parameter from Observed Data Containing Itself and Random Error, Journal of Environmental Science, Computer Science and Engineering \& Technology, Section C, (E-ISSN : 2278 - 179 X), 9(3), 473 - 486, 2020b. Available at Www.jecet.org 